\title{
Temperature-Programmed Pyrolysis \\ Hyphenated with Metastable Atom \\ Bombardment Ionization Mass Spectrometry \\ (TPPy/MAB-MS) for the Identification \\ of Additives in Polymers
}

\author{
M. Boutin,* J. Lesage, and C. Ostiguy \\ Institut de Recherche Robert-Sauvé en Santé et en Sécurité du Travail, Montreal, Quebec, Canada
}

\begin{abstract}
M. J. Bertrand
Regional Center for Mass Spectrometry, Department of Chemistry, University of Montreal, Montreal, Quebec, Canada
\end{abstract}

\begin{abstract}
Thermoanalytical techniques are currently used for the analysis of additives contained in polymers that cannot be easily dissolved, extracted, or hydrolyzed. With these techniques, the polymers are heated to liberate the additives trapped in the polymer matrix. If the polymer is heated slowly, up to its thermal degradation, the technique is called temperature-programmed pyrolysis (TPPy). For TPPy experiments, mass spectrometry is generally used as the detection method. The ionization sources commonly used in mass spectrometry, such as CI and EI, can cause fragmentation during the ionization process. Fragmentation decreases the sensitivity of the molecular ions and increases the risks of interferences with the compounds coming from the matrix. An energy-tunable ionization technique, called metastable atom bombardment (MAB), is proposed for TPPy/MS experiments. With this ionization source, the energy of ionization depends on the metastable gas used. With low-energy metastable gases such as Xe or $\mathrm{N}_{2}$, fragmentation is reduced compared to $\mathrm{CI}$, whereas with medium-energy metastable gases such as Ar or $\mathrm{Kr}$, the fragmentation is similar to that observed with CI. TPPy/MAB-MS was performed on an unknown polyurethane-based car paint. The detection of molecular ions and characteristic fragments with $\operatorname{MAB}\left(\mathrm{N}_{2}\right)$ led to the identification of two light stabilizers: Bis(1,2,2,6,6-pentamethyl-4-piperidinyl)sebacate (BPPS) and 2-(2H-benzotriazol-2-yl)-4,6di-tert-pentylphenol (PTPP). Using MAB(Ar) to simulate $\mathrm{CI}$, the molecular ion and one of the two characteristic fragments of BPPS were not detected, thus confirming the advantage of using $\operatorname{MAB}\left(\mathrm{N}_{2}\right)$ ionization for TPPy/MS experiments. (J Am Soc Mass Spectrom 2004, 15, 1315-1319) @ 2004 American Society for Mass Spectrometry
\end{abstract}

A large variety of additives are used in polymer processing to obtain compounds with the desired properties. These additives can modify the color (pigments and dyestuffs), improve or modify the mechanical properties (fillers and reinforcements), provide resistance to heat and aging (antioxidants and stabilizers), provide resistance to light degradation (UV stabilizers), improve flame resistance (flame retardants), improve processing characteristics (recycling additive), and improve the performance (anti-static/ conductive additives, plasticizers, blowing agents, lu-

Published online July 28, 2004

Address reprint requests to Dr. M. Boutin, IRSST, Programme Hygiene et Toxicology, 505 boul. de Maisonneuve Ouest, Montréal, Quebec, Canada H3A 3C2. E-mail: boutin.michel@irsst.gc.ca

*Also at the Regional Center for Mass Spectrometry, Department of Chemistry, University of Montreal, Montreal, Canada H3C 3J7. bricants, mold release agents, surfactants, preservatives) of the polymers [1]. The identification of additives accounts for a great part of the deformulation process often needed to reproduce, recycle or environmentally discard unknown polymers.

The techniques actually used for the analysis of additives in polymers are extensively reviewed by J. C. J. Bart $[2,3]$. The additives can be liberated by extraction, dissolution, or hydrolysis of the polymer and analyzed using conventional methods (e.g., HPLC, GC, MS). However, for some insoluble or cross-linked polymers, these approaches are difficult to apply and other techniques must be used. When the matrix does not interfere, non-destructive in-polymer spectroscopic techniques such as diffuse-reflectance near infrared spectroscopy [4] can be employed. In other cases, thermoanalytical techniques that consist of liberating the 
additives by heating the polymer are needed. Information about the additives can be obtained rapidly using flash pyrolysis hyphenated with mass spectrometry (Py/MS) or gas chromatography (Py/GC, Py/GC/MS). Using Py/MS, all the compounds generated during the pyrolysis of the polymer are emitted at the same time and the small amounts of additives can be masked by the interferences coming from the matrix [3]. The chromatographic separation allowed by Py/GC or Py/ GC/MS is a good way of separating the additives from the interferences and thus increasing the selectivity and sensitivity of the technique [5]. To identify additives with high molecular weight that cannot be analyzed using GC owing to their low volatility, temperatureprogrammed pyrolysis (TPPy) in combination with mass spectrometry (TPPy/MS) can be employed. TPPy consists of gradually heating the polymers to perform selective desorption of the organic additives at temperatures often below the polymer's decomposition temperature [3]. For TPPy/MS, the thermal degradation of the polymer is generally performed directly inside the mass spectrometer's ionization chamber and the high vacuum favors the analysis of high molecular weight compounds.

The extent of fragmentation is decisive in identifying additives in polymers for three reasons: (1) More structural information about the original molecule is contained in large fragments, (2) the dispersion of the additive in many fragments decreases the sensitivity, and (3) the fragmentation of the compounds coming from the matrix increases the risk of interference with the additives analyzed. Two factors influence the extent of the fragmentation: The pyrolysis temperature and the ionization source used for mass spectrometry detection. A pyrolysis temperature kept at the minimum reduces the risks of thermal degradation of the additives as well as of the matrix. On the other side, the conventional ionization sources used in mass spectrometry (EI, CI) generally cause fragmentation of the molecules during the ionization process, and sometimes the molecular ions of the additives are not observed.

A recently introduced ionization technique allowing better control of the ionization energy is proposed for TPPy/MS analysis of additives in polymers. This technique, called metastable atom bombardment (MAB) [6], is based on Penning ionization [7]: An electrophilic reaction of a metastable species with an analyte. Eq 1 represents this process:

$$
\mathrm{A}^{\mathrm{m}}+\mathrm{BC} \rightarrow \mathrm{A}+\mathrm{BC}^{+}+e^{-}
$$

The metastable species $\left(\mathrm{A}^{\mathrm{m}}\right)$ attacks a molecular orbital of the analyte (BC) from which an electron is transferred into a vacant orbital of $\mathrm{A}^{\mathrm{m}}$. Simultaneously, an electron $\left(e^{-}\right)$from the outer shell of $\mathrm{A}^{\mathrm{m}}$ is ejected into a continuum state. The highest amount of excess energy that is imparted to the analyte $\left(\mathrm{BC}^{+}\right)$upon ionization equals the difference between the energy of $\mathrm{A}^{\mathrm{m}}$ and the ion-
Table 1. Energy and lifetime of the metastable states of the gases used for metastable atom bombardment ionization [7-9]

\begin{tabular}{llll}
\hline Gas & Metastable state & Energy $(\mathrm{eV})$ & \multicolumn{1}{c}{ Lifetime (s) } \\
\hline \hline $\mathrm{He}$ & ${ }^{1} \mathrm{~S}_{\mathrm{o}}$ & 20.62 & $2.0 \times 10^{-2}$ \\
$\mathrm{He}$ & ${ }^{3} \mathrm{~S}_{1}$ & 19.82 & $9.0 \times 10^{3}$ \\
& ${ }^{3} \mathrm{P}_{\mathrm{o}}$ & 16.72 & $4.3 \times 10^{2}$ \\
$\mathrm{Ar}$ & ${ }^{3} \mathrm{P}_{2}$ & 16.62 & $2.4 \times 10^{1}$ \\
& ${ }^{3} \mathrm{P}_{\mathrm{o}}$ & 11.72 & $4.5 \times 10^{1}$ \\
$\mathrm{Kr}$ & ${ }^{3} \mathrm{P}_{2}$ & 11.55 & $5.6 \times 10^{1}$ \\
& ${ }^{3} \mathrm{P}_{\mathrm{o}}$ & 10.56 & $4.9 \times 10^{-1}$ \\
$\mathrm{Xe}$ & ${ }^{3} \mathrm{P}_{2}$ & 9.92 & $8.5 \times 10^{1}$ \\
& ${ }^{3} \mathrm{P}_{\mathrm{o}}$ & 9.45 & $7.8 \times 10^{-2}$ \\
$\mathrm{~N} \mathrm{~N}_{2}$ & ${ }^{3} \mathrm{P}_{2}$ & 8.32 & $1.5 \times 10^{2}$ \\
& $\mathrm{E}^{3} \Sigma_{\mathrm{g}}^{+}$ & 11.88 & $2 \times 10^{-4}$ \\
& $\mathrm{w}^{1} \Delta_{\mathrm{u}}$ & 9.02 & $1-5 \times 10^{-4}$ \\
& $\mathrm{a}^{1} \Pi_{\mathrm{g}}$ & 8.67 & $1.0-1.5 \times 10^{-4}$ \\
& $\mathrm{a}^{1} \Sigma_{\mathrm{u}}^{-}$ & 8.52 & 1.4 \\
& $\mathrm{~W}^{3} \Delta_{\mathrm{u}}$ & 7.32 & 17 \\
& $\mathrm{~A}^{3} \Sigma_{\mathrm{u}}^{+}$ & 6.17 & $1.0-2.6$ \\
\hline
\end{tabular}

ization potential of BC. If this excess energy is sufficient, dissociative Penning ionization can also occur as described by eq 2 :

$$
\mathrm{A}^{\mathrm{m}}+\mathrm{BC} \rightarrow \mathrm{A}+\mathrm{B}^{+\cdot}+\mathrm{C}+e^{-}
$$

Thus, by using a metastable gas that has an energy close to the ionization potential of the analyte, the internal energy of the analyte ion formed is small and fragmentation is essentially absent. However, if the energy difference is large, the reaction shown in eq 2 is favored and extensive fragmentation can result. Table 1 shows the excitation energy and the lifetime of the metastable species of the gases used for MAB ionization [7-9]. During the excitation process, each gas generates more than one metastable state. For each rare-gas, it is the metastable state with the weaker energy that is the most populated [7]. Therefore, with these gases, ionization is performed using a quasi-monoenergetic metastable atom beam. Using $\mathrm{N}_{2}$ as the ionization gas, the global ionization energy is located between the ionization energies of Xe and $\mathrm{Kr}$. Piperidine was analyzed with the different MAB gases to observe the variation in fragmentation [10]. Using $\mathrm{He}$ or $\mathrm{Ne}$, an extent of fragmentation greater than or equal to $\mathrm{EI}(70 \mathrm{eV})$ is observed. When gases providing intermediate internal energies such as $\mathrm{Ar}$ and $\mathrm{Kr}$ are used, the fragmentation observed with $\mathrm{MAB}$ is comparable to that of CI mostly involving rearrangement ions. Finally, the low energy mode of the $\operatorname{MAB}$ source $\left(\mathrm{Xe}, \mathrm{N}_{2}\right)$ yields mainly molecular ions. The MAB ionization technique has already been used to analyze flame retardants [11], dioxins and furans [12], bacteria [13], and explosives [14].

\section{Experimental}

\section{Polymer Studied}

The polymer for which the additives were analyzed was a polyurethane-based clear coating for the car industry 


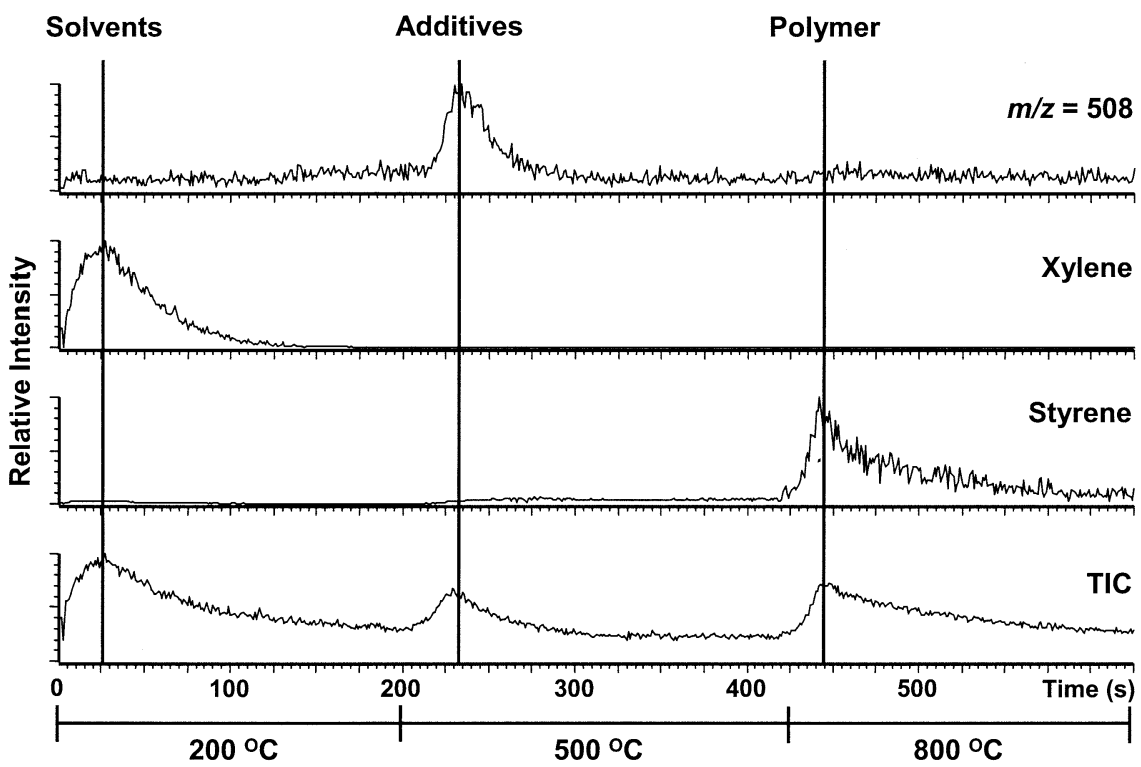

Figure 1. TPPy/MAB-MS ion chromatogram of the unknown car paint studied using $\mathrm{N}_{2}$ as ionization gas.

collected in a car repair shop just after its application. The polymer matrix was made of isocyanurate, the cyclic trimer of 1,6-hexamethylenediisocyanate (HDI), reacted with a hydroxyl-functional polyacrylate resin.

\section{TPPy/MAB-MS Analysis}

TPPy/MAB-MS experiments were conducted using a Py/MAB-Tof mass spectrometer (Dephy Technologies Inc., Montreal, Canada) optimized for thermo-analytical mass spectrometry [15]. $\mathrm{N}_{2}$ was used as the MAB ionization gas at a pressure of $85 \mathrm{mBar}$. The discharge work current was $12 \mathrm{~mA}$, and the temperature of the source was $150{ }^{\circ} \mathrm{C}$. The orthogonal-acceleration reflectron-based time-of-flight mass analyzer was operated at a push-out rate of $25-50 \mathrm{kHz}$, which ensures good sensitivity and a rapid acquisition rate compatible with pyrolysis experiments. The instrument has a mass range of $3000 \mathrm{Da}$. The pyrolyzer used was a Pyroprobe 2000 (CDS Analytical, Oxford, PA). With this apparatus, the maximum temperature allowed was $1400{ }^{\circ} \mathrm{C}$, and the permitted heating rate ranged from 0.01 to $20 \mathrm{~K} \mathrm{~ms}^{-1}$. The solid probe consisted of a quartz tube placed inside an electronically controlled, platinum heating coil. All the temperatures mentioned in this article are nominal instrument temperatures that correspond to the temperatures of the heating coil provided by the manufacturer. The temperature at the level of the sample is thus unknown and probably much lower than the nominal temperature set. For a nominal instrument temperature of $600{ }^{\circ} \mathrm{C}$, Funazukuri et al. [16] measured a sample temperature of only $275^{\circ} \mathrm{C}$.

Previous TPPy/MAB-MS experiments have been carried out on the car paint studied to identify the isocyanates generated during its thermal degradation
[17]. A temperature program, consisting of three consecutive temperature levels $\left(200^{\circ} \mathrm{C}\right.$ for $200 \mathrm{~s}, 500{ }^{\circ} \mathrm{C}$ for $225 \mathrm{~s}$, and $800{ }^{\circ} \mathrm{C}$ for $200 \mathrm{~s}$ ), was used. At $200^{\circ} \mathrm{C}$, the solvents trapped in the polymer (toluene, xylene and trimethylbenzene) were emitted, and at $800{ }^{\circ} \mathrm{C}$, the polyurethane matrix had decomposed to generate various isocyanates and styrene. To identify the additives, new experiments focusing on the $500{ }^{\circ} \mathrm{C}$ level were performed using the same temperature program. To increase the sensitivity of the additives, the weight of the pyrolyzed samples was increased to approximately $0.5 \mathrm{mg}$.

\section{Additive Identification Validation}

A pure additive, identified during the TPPy/MAB-MS experiments, was analyzed using an AutoSpec-Tof mass spectrometer (Micromass, Manchester, UK) to confirm its fragmentation pattern. The mass spectrometer was equipped with a MAB ionization source (Dephy Technologies Inc., Montreal, Canada) operated under the same conditions as during the TPPy/ MAB-MS experiments. This apparatus was also used for the exact-mass measurement used to validate the fragmentation mechanism.

\section{Results and Discussion}

\section{TPPy/MAB-MS}

The TPPy $/ \mathrm{MAB}\left(\mathrm{N}_{2}\right)$-MS ion chromatogram is shown in Figure 1. As expected, owing to the temperature program, the emission of organic compounds was separated into three steps: the solvents, the additives, and the polymer matrix. Figure $2 \mathrm{a}$ shows the mass spectra of the 

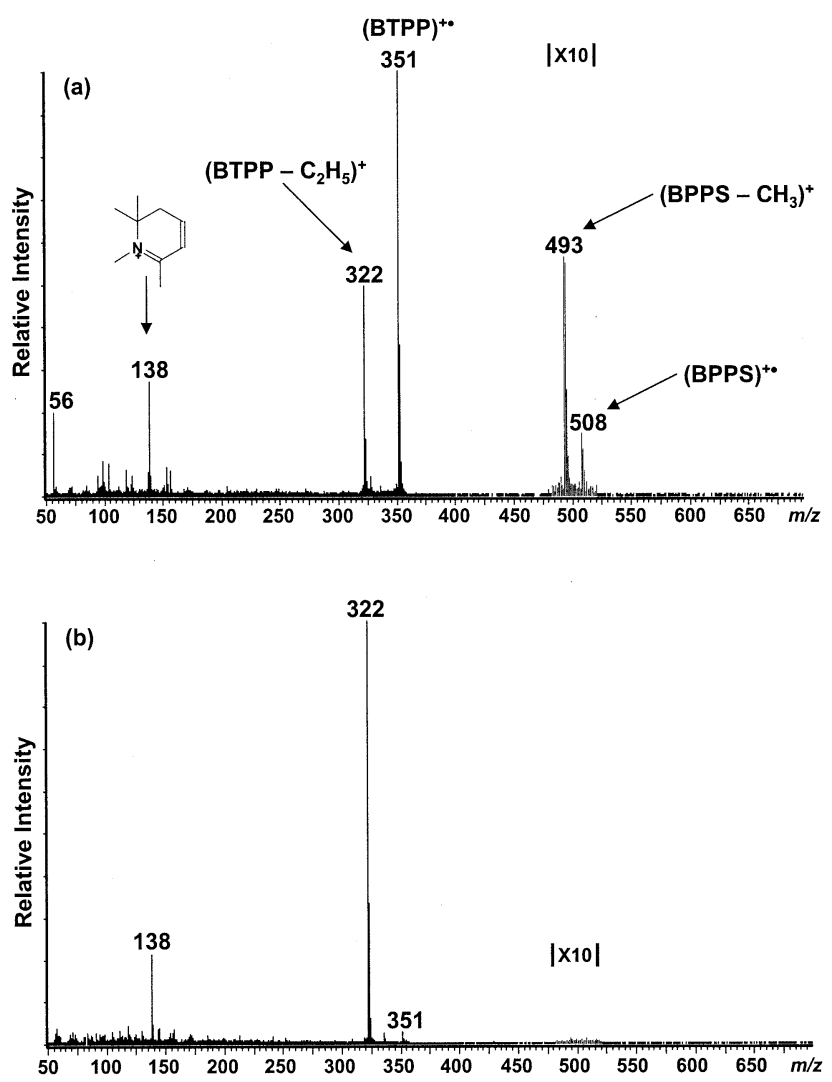

Figure 2. Mass spectrum obtained during the TPPy/MAB-MS analysis of the car paint at $500{ }^{\circ} \mathrm{C}$. (a) $\mathrm{MAB}\left(\mathrm{N}_{2}\right)$; (b) $\mathrm{MAB}(\mathrm{Ar})$.

car paint obtained at $500{ }^{\circ} \mathrm{C}$ using $\mathrm{N}_{2}$ as ionization gas. The higher $m / z$ ratio detected was 508 , which corresponds to the molecular ion of Bis(1,2,2,6,6-pentamethyl-4-piperidinyl)sebacate (BPPS) (Figure 3), a light stabilizer used in the coating industry. Two characteristic fragments of this compound were also detected at $m / z=138$ and 493 . The loss of the methyl group to generate the ion at $m / z=$ 493 comes from an $\alpha$-cleavage of the molecular ion similar to that observed for 1,2-dimethylpiperidine [18]. For the formation of the ion at $m / z=138$, a two-step mechanism is proposed in eqs 3 and 4 .

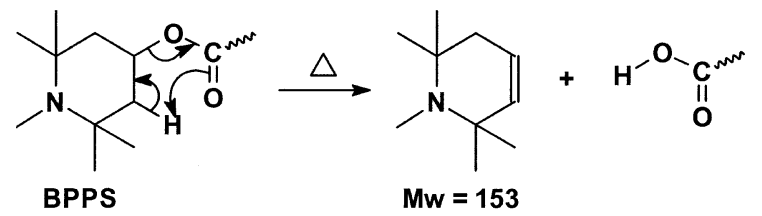<smiles>CN1C(C)(C)C=CCC1(C)C</smiles>

The molecule with a molecular weight (Mw) of 153 was probably generated during the thermal degradation of the additive according to eq 3 . Following MAB ionization, the major fragmentation pathway proposed is shown in eq 4 . The ion at $m / z=153$ loses a methyl group during $\alpha$-cleavage to generate the ion at $m / z=$ 138. This low-energy cleavage is favored by the energy stabilization gained by the appearance of electronic resonance between the two double bonds.

The dominant ion at $m / z=351$ corresponds to the molecular ion of an other light stabilizer named 2- $(2 \mathrm{H}-$ benzotriazol-2-yl)-4,6-di-tert-pentylphenol (BTPP) (Figure 3). The fragment at $m / z=322$ corresponds to the loss of an ethyl radical from one of the two di-tertpentyl groups attached to the phenol. The loss of ethyl groups was favored over the loss of methyl groups during this fragmentation process according to the "loss of the largest alkyl group" rule [18].

The TPPy/MAB-MS experiment was repeated using Ar as ionization gas to simulate CI. As shown in Figure $2 b$, under these conditions, for BPPS, only the fragment at $m / z=138$ was observed. Detection of only this fragment was not sufficient to identify this additive.

\section{Additive Identification Validation}

To validate the identification of BPPS, Tinuvin292 (Ciba Specialty Chemicals), a light stabilizer consisting of an almost pure mixture of BPPS and methyl(1,2,2,6,6pentamethyl-4-piperidinyl)sebacate (MPPS) (Figure 3),<smiles>CCCCCCCC(=O)OC1CC(C)(C)N(C)C(C)(C)C1</smiles>

$\operatorname{Bis}(1,2,2,6,6-$ pentamethyl-4-piperidinyl)sebacate (BPPS)

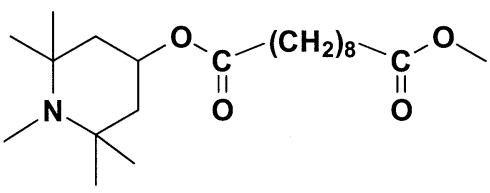

Methyl(1,2,2,6,6-pentamethyl-4-piperidinyl)sebacate (MPPS)<smiles>CCC(C)(C)c1cc(-n2nc3ccccc3n2)c(O)c(C(C)(C)CC)c1</smiles>

2-(2H-benzotriazol-2-yl)-4,6-di-tert-pentylphenol (BTPP)

Figure 3. Light stabilizers used in car paint. 


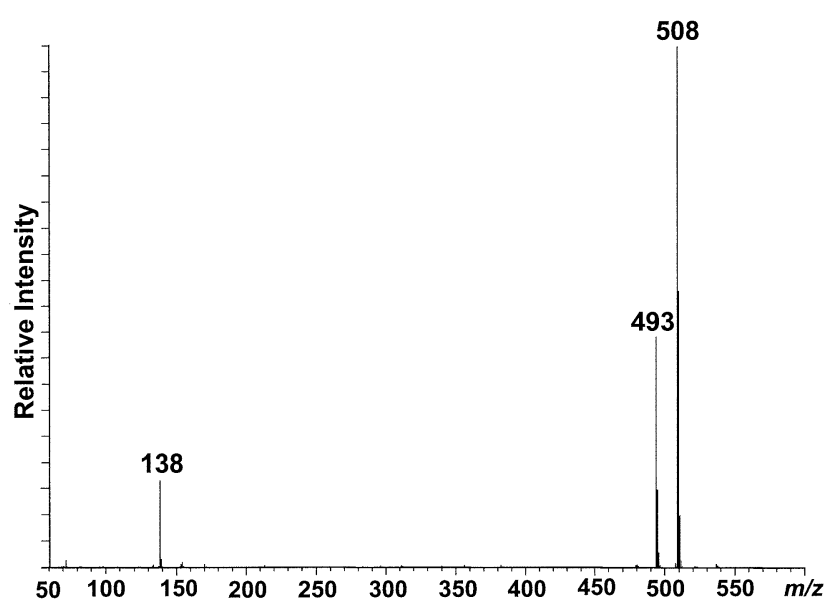

Figure 4. Mass spectrum of Bis(1,2,2,6,6-pentamethyl-4-piperidinyl)sebacate (BPPS) using $\mathrm{N}_{2}$ as MAB ionization gas.

was analyzed. The solid probe was heated to $150{ }^{\circ} \mathrm{C}$ to evaporate the MPPS. Then, the temperature of the probe was raised to $350{ }^{\circ} \mathrm{C}$ to detect the BPPS. As shown in Figure 4, the fragments detected during the analysis of the BPPS contained in the Tinuvin292 are the same as the fragments observed during the TPPy/MAB( $\left.\mathrm{N}_{2}\right)-\mathrm{MS}$ experiment. To reinforce the fragmentation mechanism proposed for BPPS, an exact-mass measurement was performed on the fragment at $m / z=138$. A difference of $-5.7 \pm 5.0 \mathrm{ppm}$ between the measured mass and the calculated mass confirmed the empirical formula of the compound proposed for the ion detected at $\mathrm{m} / \mathrm{z}=138$ $\left(\mathrm{C}_{9} \mathrm{H}_{16} \mathrm{~N}\right)$. No other empirical formula is closer than 54.3 ppm from the exact-mass measured.

\section{Conclusion}

The MAB ionization source was used during TPPy/MS experiments for the analysis of a polyurethane-based car paint. With a low-energy MAB gas $\left(\mathrm{N}_{2}\right)$, molecular ions and characteristic fragments of BPPS and BTPP, two light stabilizers, were observed. Detection of the molecular ion of BPPS, necessary for the identification of this additive, was not possible using a mediumenergy MAB gas (Ar) that simulates the fragmentation occurring during CI. These results confirmed the advantage of using $\mathrm{MAB}\left(\mathrm{N}_{2}\right)$ compared to $\mathrm{CI}$ or other medium- or high-energy ionization techniques to identify additives in polymers. According to the supplier's recommendations, the concentration of BPPS and BTPP in the paint, based on solid weight, must be between 0.5 and $3 \%$. Additives at low concentration can thus be identified using TPPy/MAB-MS. After the molecular ion of the additives was identified using $\operatorname{MAB}\left(\mathrm{N}_{2}\right)$, if the structural information on the mass spectrum is not sufficient for structural elucidation, complementary information can be obtained by using a more energetic MAB gas, that increases the fragmentation, such as Ar.

\section{Acknowledgments}

This study was made possible by financial support of the Institut de recherche Robert-Sauvé en santé et en sécurité du travail du
Québec (IRSST), the Natural Sciences and Engineering Research Council of Canada (NSERC), and the Fonds québécois de la recherche sur la nature et les technologies (FQRNT). The authors especially thank Mr. Mike Evans for the help provided during this research.

\section{References}

1. Gächter, R.; Müller, H. Plastics Additives Handbook, 4th ed; Hansa: Munich, 1993.

2. Bart, J. C. J. Polymer Additive Analysis at the Limits. Polym. Degrad. Stab. 2003, 82, 197-205.

3. Bart, J. C. J. Polymer/Additive Analysis by Flash Pyrolysis Techniques. J. Anal. Appl. Pyrolysis 2001, 58/59, 3-28.

4. Molt, K.; Ihlbrock, D. Principles and Applications of Quality Control by Near Infrared Spectroscopy Using the Example of Polymer Additives. Fresenius J. Anal. Chem. 1994, 348, 523-529.

5. Herrera, M.; Matuschek, G.; Kettrup, A. Fast Identification of Polymer Additives by Pyrolysis-Gas Chromatography/Mass Spectrometry. J. Anal. Appl. Pyrolysis 2003, 70, 35-42.

6. Faubert, D.; Paul, G. J. C.; Giroux, J.; Bertrand, M. J. Selective Fragmentation and Ionization of Organic Compounds Using an Energy-Tunable Rare-Gas Metastable Beam Source. Int. J. Mass Spectrom. Ion Processes 1993, 124, 69-77.

7. Siska, P. E. Molecular-Beam Studies of Penning Ionization. Rev. Mod. Phys. 1993, 65, 337-412.

8. Delacroix, J. L.; Matos Ferreira, C.; Ricard, A. Atomes et molécules métastables dans les gaz ionisés; Centre National de la Recherche Scientifique: Paris, 1975; p 21.

9. Slanger, T.G. In Reactions of Small Transient Species: Kinetics and Energetics; Fontijn, A.; Clyne, M. A. A., Eds.; Academic Press: New York, 1983; pp 293-302.

10. Faubert, D. Développement et application d'une source d'ionisation utilisant le bombardement par atomes métastables; Montreal University: Montreal, 1999, pp 135-137.

11. Ikonomou, M. G.; Rayne, S. Chromatographic and Ionization Properties of Polybrominated Diphenyl Ethers Using GC/ High-Resolution MS with Metastable Atom Bombardment and Electron Impact Ionization. Anal. Chem. 2002, 74, 52635272.

12. Moore, S. Use of the Metastable Atom Bombardment (MAB) Ion Source for the Elimination of PCDE Interference in PCDD/PCDF analysis. Chemosphere 2002, 49, 121-125.

13. Letarte, S.; Mousselmal, M.; Faubert, D.; Bertrand, M. J. Use of MAB-MS for the Characterization of Bacteria. Proceedings of the 46th ASMS Conference on Mass Spectrometry and Allied Topics; Orlando, FL, 1998.

14. Forest, A.; Martin, P.; Faubert, D.; Sanchez, G.; Bertrand, M. J. Evaluation of Py-MAB-TOF as a Technique for the Detection of Explosives by Direct Analysis of Soil Samples. Proceedings of the 48th ASMS Conference on Mass Spectrometry and Allied Topics; Long Beach, CA, 2000.

15. Martin, P.; Forest, A.; Peraldi, O.; Bertrand, M. J. A Benchtop Mass Spectrometer Optimized for Pyrolysis Mass Spectrometry: PY-MAB-TOF. Proceedings of the 48th ASMS Conference on Mass Spectrometry and Allied Topics; Long Beach, CA, 2000.

16. Funazukuri, T.; Hudgins, R. R.; Silverston, P. L. Product Distribution for Flash Pyrolysis of Cellulose in a Coil Pyrolyzer. J. Anal. Appl. Pyrolysis 1987, 10, 225-249.

17. Boutin, M.; Lesage, J.; Ostiguy, C.; Bertrand, M. J. Comparison of EI and Metastable Atom Bombardment Ionization for the Identification of Polyurethane Thermal Degradation Products. J. Anal. Appl. Pyrolysis 2003, 70, 505-517.

18. McLafferty, F. W.; Turecek, F. Interpretation of Mass Spectra, 4th ed; University Science Books: Sausalito, CA, 1993, pp 53, $185,186$. 